\title{
Auction mechanisms and the measurement of WTP and WTA
}

\author{
Jason F. Shogren ${ }^{\mathrm{a}, *}$, Sungwon Cho ${ }^{\mathrm{b}}$, Cannon Koo ${ }^{\mathrm{c}}$, John List ${ }^{\mathrm{d}}$, \\ Changwon Park ${ }^{\mathrm{e}}$, Pablo Polo ${ }^{\mathrm{f}}$, Robert Wilhelmi ${ }^{\mathrm{b}}$ \\ ${ }^{a}$ Department of Economics and Finance, University of Wyoming, P.O. Box 3985, \\ 121 Ross Hall, Laramie, WY 82071, USA \\ b Iowa State University, Ames, IA 50011, USA \\ ${ }^{c}$ AC Nielson, Deerfield, IL 60015, USA \\ ${ }^{\mathrm{d}}$ University of Central Florida, Orlando, FL 32816-1400, USA \\ e ChoHung Bank, Seoul, South Korea \\ ${ }^{\mathrm{f}}$ University of Carabobo, Valencia, Venezuela
}

Received 23 August 1999; received in revised form 28 April 2000; accepted 3 May 2000

\begin{abstract}
We evaluate the impact of three auction mechanisms - the Becker-DeGroot-Marschak mechanism, the second-price auction, and the random $n$ th-price auction — in the measurement of willingness to pay (WTP) and willingness to accept (WTA) measures of value. Our results show that initial bidding in trial 1 in each auction does not contradict the endowment effect; but that, if it is the endowment effect that governs people's initial bidding behavior, it can be eliminated with repetitions of a second-price or random $n$ th-price auction; and if the thesis is that the effect should persist across auctions and across trials is right, our results suggest that there is no fundamental endowment effect. (C) 2001 Elsevier Science B.V. All rights reserved.
\end{abstract}

JEL classification: C91; D44; Q2

Keywords: Auction; Endowment effect; Willingness to pay; Willingness to accept; Random $n$ th-price auction

\section{Introduction}

Theory suggests that with small income effects and many available substitutes, the willingness to pay (WTP) for a commodity and the willingness to accept (WTA) compensation to sell the same commodity should be about equal (Willig, 1976; Randall and Stoll, 1980;

\footnotetext{
${ }^{*}$ Corresponding author. Tel.: +1-307-766-5430; fax: +1-307-766-5090.

E-mail address: jramses@uwyo.edu (J.F. Shogren).
} 
Hanemann, 1991). If the good is available in an active market at the market rate, a person's WTP and WTA should be similar. And if people face similar transaction costs, WTP and WTA should be similar across people as well.

But in their seminal work, Kahneman et al. (1990) (KKT) report experimental evidence of a behavioral anomaly to this theory. This anomaly - an endowment effect - exists when people offer to sell a commonly available good in their possession at a substantially higher rate than they will pay for the identical good not in their possession (e.g. pens and coffee mugs). Using the incentive-compatible Becker et al. (1964) mechanism to elicit preferences, KKT make the case for a fundamental endowment effect, which challenges a critical presumption underlying economic theory — preferences are no longer independent of endowments.

In contrast, the lab valuation experiments of Shogren et al. (1994a) (SSHK) observed no significant divergence between WTP and WTA for similar goods in a distinct experimental design that used a demand revealing second-price auction with endogenous market-clearing price feedback. ${ }^{1}$ The open question is why the different results in KKT and SSHK? Previous lab work has illustrated that bidding behavior is sensitive to auction design, ${ }^{2}$ which leads one to suspect that the choice of auction mechanism might be the reason behind the conflicting results (Grether, 1994). Unfortunately, too many differences exist across experimental parameters to confirm or reject this suspicion.

Herein, we address this auction-dependence question with an experiment design that uses the auction mechanism as a treatment. The thesis is that if it is the endowment effect that accounts for the observations of KKT, then what they interpret as the endowment effect should be observable and persistent for any mechanism used to elicit WTP and WTA, provided the mechanism is incentive compatible. We test this thesis by evaluating the impact of three auction mechanisms in the measurement of willingness to pay (WTP) and willingness to accept (WTA) measures of value for goods with close substitutes the Becker-DeGroot-Marschak mechanism with random, exogenous price feedback as used by KKT, the second-price auction with endogenous market-clearing price feedback as used by Shogren et al. (1994a), and a new random $n$ th-price auction with endogenous market-clearing price feedback.

Our results show that initial bidding behavior in each auction does not contradict KKT's concept of an endowment effect. But if it is an endowment effect that originally governs bidding, our results show that the effect can be eliminated with repetitions of a second-price or random $n$ th-price auction. And if the thesis is correct that a fundamental endowment effect should persist across auction mechanisms and across trials, our experiment shows that there is no fundamental endowment effect.

\section{Experimental design and procedures}

Table 1 summarizes the original design parameters in KKT and SSHK, and then shows the details of our new design in which the auction mechanism is the treatment, holding

\footnotetext{
${ }^{1}$ See Knetsch and Sinden (1984), Coursey et al. (1987), and Brookshire and Coursey (1987) for the classic early work on measures of value and the design of lab valuation experiments.

${ }^{2}$ See for example Smith (1982) and Plott (1986) on market outcomes in double oral versus posted-price auctions.
} 
Table 1

Summary of experimental design parameters

\begin{tabular}{|c|c|c|c|c|}
\hline \multirow[t]{2}{*}{ Design parameter } & \multicolumn{2}{|l|}{ Original experimental designs } & \multicolumn{2}{|l|}{ New experimental design } \\
\hline & Original Kahneman et al. (1990) & Original Shogren et al. (1994a) & New experiments & Random $n$ th-price auction \\
\hline Auctioned goods & Tokens, pens and mugs & Candy bar, sandwich and mugs & Candy bar and mugs & Candy bar and mugs \\
\hline Initial monetary endowment & None & $\begin{array}{l}\text { US\$3: candy bar, US\$ } \\
\text { 15: sandwich or mug }\end{array}$ & US\$ 15 & US\$ 15 \\
\hline Number of trials & Varied between 3 and 7 & $\begin{array}{l}\text { 5: candy bar, 20: } \\
\text { sandwich, 10: mugs }\end{array}$ & 10: candy bar, 10: mugs & 10: candy bar, 10: mugs \\
\hline Retail price information & Provided for some treatments & None provided & None provided & None provided \\
\hline Subject participation & In-class & Voluntary & Voluntary & Voluntary \\
\hline Number of subjects per session & $\begin{array}{l}\text { Varied between } 30 \text { and } 44 \\
\text { Simon Fraser University }\end{array}$ & 12-15 Iowa State University & $\begin{array}{l}\text { 8-10: SPA, 20: BDM } \\
\text { Iowa State University }\end{array}$ & $\begin{array}{l}\text { 10: random } n \text { th-price } \\
\text { auction University } \\
\text { of Central Florida }\end{array}$ \\
\hline Auction institution & $\begin{array}{l}\text { Becker-DeGroot-Marschak } \\
\text { mechanism (BDM) }\end{array}$ & Second-price auction (SPA) & Both the BDM and the SPA & $\begin{array}{l}\text { Random } n \text { th-price } \\
\text { auction }\end{array}$ \\
\hline
\end{tabular}


other design parameters constant. The key experimental parameters in our new design are: (i) auctioned goods - a brand-name candy bar in Stage 1 and an Iowa State University coffee mug in Stage 2; (ii) initial monetary endowment - US\$ 15 paid up-front; (iii) number of trials - ten trials per experiment, in which we control for wealth effects by randomly selecting one of the ten trials to be the binding trial; (iv) retail price information on the commodities - none was provided; (v) subject participation - voluntary participants from the student population at Iowa State University; (vi) number of subjects per session - 8-10 subjects in the second-price auctions and 20 for the BDM mechanism; and (vii) the auction mechanism - defined immediately below.

We used the Becker-DeGroot-Marschak (BDM) mechanism used in KKT's Fifth Experimental Treatment. The BDM separates what people say from what they pay so a person's weakly dominant strategy is to state her true WTP or WTA in BDM mechanism. We run the BDM mechanism auction as follows. Twenty subjects were randomly divided into two subgroups of 10 buyers and 10 sellers. Monitors gave each seller a candy bar in Stage 1 (a coffee mug in Stage 2), which he or she could take home or sell at the auction. Each buyer had the option to buy the commodity in the auction. Each buyer and seller were asked to determine independently and privately their maximum WTP or minimum WTA by marking an ' $\mathrm{X}$ ' on a recording sheet listing a price schedule such as

\begin{tabular}{lll}
\hline & I will buy (sell) & I will not buy (sell) \\
\hline & - & - \\
If the price is US\$ 0.40 & - & - \\
If the price is US\$ 0.30 & - & - \\
If the price is US\$ 0.20 & - & - \\
\hline
\end{tabular}

The candy bar price range in Stage 1 was from US\$ 0 to US\$ 1.90, in US\$ 0.10 increments; the coffee mug price range in Stage 2 was from US\$ 0 to US\$ 9.50, in US\$ 0.50 increments. After collecting all recording sheets from buyers and sellers, one price from the sheet was selected randomly. If a buyer was willing to pay at least the random price, he or she bought the commodity. ${ }^{3}$ If the seller was willing to accept less than or equal to the random price, he or she sold the commodity. The random price and how many buyers and sellers were willing to buy and sell at the random price was recorded on the blackboard as public information. After the tenth trial in each stage, one of the 10 trials was randomly selected as the binding trial that determined take-home pay. ${ }^{4}$

\footnotetext{
${ }^{3}$ To save on a subject's patience in the experiment, a person only checked his or her maximum WTP or minimum WTA; he or she did not check all those prices below the maximum WTP or above the minimum WTA. But he or she knew that prices below the maximum WTP or above the minimum WTA were presumed to be 'checked' as well.

${ }^{4}$ As in KKT and SSHK valuation experiments, the experimental instructions that produced this data explicitly told subjects that telling the truth was the best bidding strategy, and only one trial was binding so that only one unit of the good was sold. Subjects reading these explicit instructions should have viewed the experiment as a set of one-shot auctions repeated over several times rather than as a repeated auction with multiple units for sale. Whether they did so is an open question.
} 
The second-price auction (SPA) was the same as in Shogren et al. (1994a). ${ }^{5}$ In a second-price auction, a person's weakly dominant strategy is to reveal their true WTP or WTA (Vickrey, 1961). In the WTP case, overbidding increases the likelihood that a subject will have to pay more for the good than desired, underbidding increases the chance that he will not win what he could have won if he had stated his true preferences. In the WTP treatment for each trial in each stage, bidders were asked to record, privately and independently, the maximum he or she was willing to pay for the candy bar (Stage 1) or coffee mug (Stage 2) on a recording sheet. No intervals are used as in the BDM mechanism, subjects simply wrote a numerical value on the sheet. The monitors collected the recording cards, and then posted the identification number of the highest bidder and the market-clearing price — the second highest bid — on the blackboard as public information.

In the WTA treatments, monitors gave each subject a candy bar in Stage 1, and a coffee mug in Stage 2. For each trial in each stage, subjects wrote their minimum WTA to sell the commodity on their recording sheet. Again monitors posted the identification number of the lowest bidder and the market-clearing price - the second lowest bid, on the blackboard as public information. After the tenth trial, in each stage for both the WTP and WTA treatments, the monitors selected randomly one of the ten trials as the binding trial.

Standard experimental procedures were followed. The instructions are available on request from the authors. The auctions were conducted in three sessions on the same day at Iowa State University. Different subjects participated in each session for a total of 78 participants. Each session was completed within $2 \mathrm{~h}$.

\section{Experimental results and discussion}

Tables 2 and 3 present the summary statistics of the experimental results on the BDM and SPA treatments. In the BDM treatment, the average selling price exceeded the average buying price for all ten trials in both the candy bar and coffee mug stages. This also holds for the median bids. The average and median WTA/WTP ratios remain relatively constant throughout the ten trials, ranging from 1.5 to 1.8 for the candy bar and 1.4 to 1.6 for the coffee mug. In all trials for the candy bar, we reject the null hypothesis that the mean WTP and WTA are equal, at the $p<0.01$ level using both a small sample $t$-test and a Mann-Whitney $U$-test. For the coffee mug, we reject the central tendency null in all trials at the 5 or $10 \%$ level, again using both a $t$-test and a Mann-Whitney $U$-test.

The bidding behavior in the second-price auction (SPA) followed a different pattern. As illustrated in Table 3, bidding behavior in trial 1 does not contradict KKT's concept of an endowment effect. The average and median WTA bid was significantly greater than the average or median WTP bid in trial 1. The question though is whether this pattern holds with experience.

\footnotetext{
${ }^{5}$ The second-price auction has not been the acme of perfection in always revealing induced preferences accurately. See for example Kagel (1995) and Hoffman et al. (1993) for more on the mixed evidence and guarded support for second-price auction in induced valuation experiments. See Shogren et al. (1994b) for some evidence that the second-price auction seems relatively robust in revealing non-induced preferences given alternative configurations of format and complexity.
} 
Table 2

Summary statistics of the Becker-DeGroot-Marschak auction ${ }^{\text {a }}$

\begin{tabular}{|c|c|c|c|c|c|c|c|c|c|c|c|c|}
\hline \multirow[t]{2}{*}{ Good } & \multirow[t]{2}{*}{ Value measure } & & \multicolumn{10}{|l|}{ Trial } \\
\hline & & & 1 & 2 & 3 & 4 & 5 & 6 & 7 & 8 & 9 & 10 \\
\hline \multirow[t]{8}{*}{ Candy } & WTP & Mean (US\$) & 0.58 & 0.50 & 0.54 & 0.54 & 0.53 & 0.53 & 0.47 & 0.48 & 0.51 & 0.51 \\
\hline & $N=20$ & Median & 0.50 & 0.50 & 0.50 & 0.50 & 0.50 & 0.50 & 0.50 & 0.50 & 0.50 & 0.50 \\
\hline & & Variance & 0.121 & 0.093 & 0.071 & 0.070 & 0.080 & 0.084 & 0.097 & 0.092 & 0.075 & 0.079 \\
\hline & WTA & Mean & 0.92 & 0.90 & 0.86 & 0.82 & 0.83 & 0.78 & 0.80 & 0.79 & 0.78 & 0.78 \\
\hline & $N=20$ & Median & 0.90 & 1.00 & 0.95 & 0.85 & 0.80 & 0.80 & 0.80 & 0.80 & 0.80 & 0.80 \\
\hline & & Variance & 0.067 & 0.086 & 0.072 & 0.105 & 0.073 & 0.067 & 0.087 & 0.092 & 0.091 & 0.114 \\
\hline & Ratio of mean WTA/WTP & & 1.59 & 1.80 & 1.59 & 1.52 & 1.57 & 1.47 & 1.70 & 1.65 & 1.53 & 1.53 \\
\hline & $t$-test of means & & $-3.5^{\mathrm{b}}$ & $-4.2^{\mathrm{b}}$ & $-3.8^{\mathrm{b}}$ & $-2.9^{\mathrm{b}}$ & $-3.4^{\mathrm{b}}$ & $-2.9^{\mathrm{b}}$ & $-3.4^{\mathrm{b}}$ & $-3.2^{\mathrm{b}}$ & $-2.9^{\mathrm{b}}$ & $-2.7^{\mathrm{b}}$ \\
\hline \multirow[t]{8}{*}{ Mug } & WTP & Mean (US\$) & 2.40 & 2.40 & 2.25 & 2.28 & 2.25 & 2.25 & 2.23 & 2.23 & 2.10 & 2.18 \\
\hline & $N=20$ & Median & 1.75 & 1.75 & 1.75 & 1.75 & 1.75 & 1.75 & 1.75 & 1.75 & 1.25 & 1.50 \\
\hline & & Variance & 4.200 & 4.700 & 4.540 & 4.144 & 3.961 & 3.961 & 3.802 & 3.802 & 3.085 & 3.928 \\
\hline & WTA & Mean & 3.68 & 3.55 & 3.50 & 3.40 & 3.40 & 3.35 & 3.40 & 3.43 & 3.35 & 3.13 \\
\hline & $N=20$ & Median & 3.25 & 3.50 & 3.25 & 3.00 & 3.00 & 3.00 & 3.00 & 3.00 & 3.00 & 3.00 \\
\hline & & Variance & 5.955 & 5.287 & 5.553 & 5.726 & 5.674 & 5.134 & 5.463 & 5.349 & 5.108 & 5.628 \\
\hline & Ratio of mean WTA/WTP & & 1.53 & 1.46 & 1.56 & 1.49 & 1.51 & 1.49 & 1.52 & 1.54 & 1.60 & 1.44 \\
\hline & $t$-test of means & & $-1.8^{\mathrm{c}}$ & $-1.6^{\mathrm{d}}$ & $-1.8^{\mathrm{e}}$ & $-1.6^{\mathrm{f}}$ & $-1.6^{\mathrm{f}}$ & $-1.6^{\mathrm{f}}$ & $-1.7^{\mathrm{c}}$ & $-1.8^{\mathrm{e}}$ & $-2.0^{\mathrm{e}}$ & $-1.4^{\mathrm{f}}$ \\
\hline
\end{tabular}

${ }^{\mathrm{a}} \mathrm{H}_{0}:$ mean $_{\mathrm{WTP}}-$ mean $_{\mathrm{WTA}}=0 ; \mathrm{H}_{\mathrm{A}}:$ mean $_{\mathrm{WTP}}-$ mean $_{\mathrm{WTA}}<0$.

${ }^{b} t$-test: reject $\mathrm{H}_{0}$ at the $1 \%$ level; Mann-Whitney $U$-test: reject $\mathrm{H}_{0}$ at the $1 \%$ level.

${ }^{c} t$-test: reject $\mathrm{H}_{0}$ at the $5 \%$ level; Mann-Whitney $U$-test: reject $\mathrm{H}_{0}$ at the $10 \%$ level.

${ }^{\mathrm{d}} t$-test: reject $\mathrm{H}_{0}$ at the $10 \%$ level; Mann-Whitney $U$-test: reject $\mathrm{H}_{0}$ at the $5 \%$ level.

${ }^{\mathrm{e}} t$-test: reject $\mathrm{H}_{0}$ at the $5 \%$ level; Mann-Whitney $U$-test: reject $\mathrm{H}_{0}$ at the $5 \%$ level.

${ }^{\mathrm{f}} t$-test: reject $\mathrm{H}_{0}$ at the $10 \%$ level; Mann-Whitney $U$-test: reject $\mathrm{H}_{0}$ at the $10 \%$ level. 
Table 3

Summary statistics of the second-price auction

\begin{tabular}{|c|c|c|c|c|c|c|c|c|c|c|c|c|}
\hline \multirow[t]{2}{*}{ Good } & \multirow[t]{2}{*}{ Value measure } & & \multicolumn{10}{|l|}{ Trial } \\
\hline & & & 1 & 2 & 3 & 4 & 5 & 6 & 7 & 8 & 9 & 10 \\
\hline \multirow[t]{8}{*}{ Candy } & WTP & Mean (US\$) & 0.56 & 0.62 & 0.63 & 0.70 & 0.68 & 0.72 & 0.69 & 0.71 & 0.73 & 0.75 \\
\hline & $N=18$ & Median & 0.53 & 0.63 & 0.62 & 0.75 & 0.72 & 0.80 & 0.70 & 0.78 & 0.86 & 0.90 \\
\hline & & Variance & 0.090 & 0.086 & 0.092 & 0.102 & 0.098 & 0.174 & 0.103 & 0.114 & 0.118 & 0.123 \\
\hline & WTA & Mean & 0.78 & 0.84 & 0.65 & 0.62 & 0.89 & 0.67 & 0.51 & 0.64 & 0.64 & 3.00 \\
\hline & $N=20$ & Median & 0.75 & 0.60 & 0.50 & 0.45 & 0.43 & 0.37 & 0.29 & 0.29 & 0.29 & 0.26 \\
\hline & & Variance & 0.169 & 1.033 & 0.376 & 0.363 & 4.631 & 1.199 & 0.530 & 1.267 & 1.278 & 123.57 \\
\hline & Ratio of mean WTA/WTP & & 1.39 & 1.35 & 1.03 & 0.89 & 1.31 & 0.93 & 0.74 & 0.90 & 0.88 & 4.00 \\
\hline & $t$-test of means & & $-1.9^{\mathrm{c}}$ & -0.9 & -0.1 & 0.5 & -0.4 & 0.2 & 1.0 & 0.3 & 0.3 & -0.9 \\
\hline \multirow[t]{8}{*}{ Mug } & WTP & Mean (US\$) & 2.22 & 2.73 & 2.90 & 3.19 & 3.38 & 3.34 & 3.33 & 3.58 & 3.42 & 3.28 \\
\hline & $N=18$ & Median & 1.75 & 3.00 & 3.25 & 3.40 & 3.63 & 3.53 & 3.74 & 3.80 & 3.87 & 3.73 \\
\hline & & Variance & 2.142 & 1.407 & 1.573 & 1.805 & 1.855 & 2.821 & 2.726 & 2.276 & 2.918 & 2.687 \\
\hline & WTA & Mean & 5.52 & 4.56 & 3.77 & 3.58 & 3.52 & 3.16 & 3.08 & 2.45 & 3.33 & 3.44 \\
\hline & $N=20$ & Median & 4.88 & 5.00 & 4.48 & 3.75 & 4.01 & 3.18 & 3.25 & 1.13 & 3.50 & 4.00 \\
\hline & & Variance & 15.912 & 13.397 & 6.971 & 6.775 & 5.749 & 6.364 & 6.448 & 5.498 & 7.073 & 8.304 \\
\hline & Ratio of mean WTA/WTP & & 2.49 & 1.67 & 1.30 & 1.12 & 1.04 & 0.95 & 0.92 & 0.68 & 0.97 & 1.05 \\
\hline & $t$-test of means & & $-3.4^{\mathrm{b}}$ & $-2.1^{\mathrm{d}}$ & $-1.3^{\mathrm{e}}$ & -0.6 & -0.2 & 0.3 & 0.4 & $1.8^{\mathrm{d}}$ & 0.1 & -0.2 \\
\hline
\end{tabular}

${ }^{\mathrm{a}} \mathrm{H}_{0}$ : mean $_{\mathrm{WTP}}-$ mean $_{\mathrm{WTA}}=0 ; \mathrm{H}_{\mathrm{A}}$ : mean $_{\mathrm{WTP}}-$ mean $_{\mathrm{WTA}}<0$.

${ }^{\mathrm{b}} t$-test: reject $\mathrm{H}_{0}$ at the $1 \%$ level; Mann-Whitney $U$-test: reject $\mathrm{H}_{0}$ at the $1 \%$ level.

${ }^{c} t$-test: reject $\mathrm{H}_{0}$ at the $5 \%$ level; Mann-Whitney $U$-test: reject $\mathrm{H}_{0}$ at the $5 \%$ level.

${ }^{\mathrm{d}} t$-test: reject $\mathrm{H}_{0}$ at the $5 \%$ level.

${ }^{\mathrm{e}} t$-test: reject $\mathrm{H}_{0}$ at the $10 \%$ level. 
Unlike the BDM treatment, WTA offers decreased and WTP bids increased after the initial trial in each SPA. The average and median WTA/WTP ratios decline throughout the ten trials, decreasing from 1.4 in trial 1 to 0.88 in trial 9 for the candy bar (the ratio in trial 10 was 4 , including an extreme outlier bid of US\$ 50). ${ }^{6}$ The average WTA-WTP ratio decreased from 2.5 in trial 1 to 1.05 in trial 10 for the coffee mug. In trials 2-10 for the candy bar, we cannot reject the null hypothesis that the mean WTP and WTA are equal at the $10 \%$ level using a $t$-test and at the 5\% level using a Mann-Whitney $U$-test. For the coffee mug, we cannot reject the null in trials 3-7 and 9-10 at the 5\% level using the $t$-test, and we cannot reject the null in trials $2-10$ at the $1 \%$ level using the Mann-Whitney $U$-test. The value disparity faded away in the second-price auction with feedback on the endogenous market-clearing price - average WTP and WTA value measures are not statistically different. ${ }^{7}$

In sum, our experiments show that while initial bids do not contradict, but do not prove either, what KKT call the endowment effect. ${ }^{8}$ But the results also show that repetitions of a second-price auction can remove the endowment effect, if that is what is indeed originally governing bidding behavior. And if the idea is that the effect should persist across auctions and trials is correct, our results suggest no fundamental endowment effect exists.

Although our findings are compelling, two counter-arguments can be used to challenge the results - affiliated bidding behavior and a top dog effect. Since our experimental design herein does not allow us to test either conjecture directly, we appeal to additional experimental work. As we see below, the results from this lab work reveals little empirical support for either conjecture.

First, concern has been voiced that most bidders walk into a valuation auction cold, and thus the common uncertainty about the value of the good might create 'affiliated' values or beliefs (see Milgrom and Weber, 1982). Affiliation exists, for example, when a posted high-bid induces low bidders to increase their bids. The posted bid affects behavior because prices send information to bidders about commonly perceived, but unknown, characteristics of the product. List and Shogren (1999) reject this affiliation hypothesis for familiar goods - the evidence revealed no pattern of affiliated bidding behavior in approximately 40 treatments which use a repeated second-price auction. They found that post market-clearing

\footnotetext{
${ }^{6}$ The SPA clearly was not demand revealing in trial 10 for this subject.

${ }^{7}$ Consider the percentage change in average bids with repeated market experience for the candy bar and mug in each auction. Using trial 1 bids as the benchmark, the BDM mechanism both the mean WTP and WTA decline slowly over periods, falling by $9-15 \%$ in trial 10 . Given that the market price in the BDM auction was exogenously determined and independent of bidding behavior, there are minor adjustments in bidding behavior. In contrast, average WTP and WTA, in the second-price auction take separate and more pronounced paths - WTP increases by $34 \%$ (candy bar) and $48 \%$ (mug) by trial 10, while WTA declines by $18 \%$ (candy bar-trial 9) and 38\% (mug-trial 10). Since the market price is potentially a function of anyone's bid, bidding behavior adjusts as the initial WTA offers fall and initial WTP bids increase. As a comparative benchmark, the percentage change in bidding behavior from the second-price auction/mug treatments from Shogren et al. (1994a) is similar to our new second-price auctions. The average WTP bid increases by about $30 \%$ by trial 10 , while the WTA bid (with and without a secondary mug sale market) declines by over $60 \%$.

${ }^{8}$ While it can be argued that a value disparity persisted even in Kahneman et al.'s first auction designs, in which the market price was endogenously determined, it is possible that the fixed intervals used to elicit values in these discrete-choice auction prevented the subjects from making small changes in their bids, thereby potentially discouraging changes in initial WTP bids and WTA offers. This question seems worth examination in future research.
} 
prices did not affect average bidding behavior for familiar goods in the second-price auction with feedback.

Second, some observers have suggested that the second-price auction creates an environment that is too competitive to elicit people's true WTA and WTP. People might be submitting bids to win for winning sake. They might bid WTP up and WTA down simply to walk out of the experiment as the 'top dog' among their peers. While this is a theoretical possibility, experimental evidence provides no support for this conjecture. Recent lab results designed to test the second-price auction shows that nearly $90 \%$ of all bids were less than or equal to a bidder's private induced value (e.g. Shogren and Hayes, 1997; Cherry et al., 2000). This evidence suggests that the top dog effect is not a universal phenomenon in valuation experiments, and the case remains unarticulated by its supporters as to why it should exist for one set of goods over another.

\section{The random $n$ th-price auction: design and results}

But these findings still cannot completely explain the observations of Knetsch et al. (1998). Knetsch et al. ran a second-price and a ninth-price auction with repeated trials for a familiar good, and still detected large gaps in WTP and WTA values. They concluded that the 'endowment effect remains robust over repeated trials, and that contrary to common understanding, the Vickrey auction may not be demand revealing'. They make the reasonable case that the uniform auction is not necessarily the preferred mechanism if fails to engage off-the-margin bidders - i.e. bidders whose value is far below or above the market-clearing price.

These off-the margin bidders in the second and ninth price auctions might have less incentive to make sincere bids if they believe they have no chance to win or to lose the auction at a profit. The second price auction might not engage low value bidders, while the ninth price auction might not engage high value bidders. Ninth price auction bidders realize the support of bids is significantly below their value and therefore, can afford to submit false bids without being punished by the market. And in fact, lab evidence using induced values does not contradict this conjecture - bidders off-the-margin of the market-clearing price often do not bid sincerely (see for example, Miller and Plott, 1985; Franciosi et al., 1993).

We now introduce a new auction mechanism - the random $n$ th-price auction - that attempts to overcome this issue. The auction attempts to engage each and every bidder by combining the best parts of the BDM and second price mechanisms - a random but endogenously determined market-clearing price. Randomness to keep all bidders in the auction and reduce their incentive to chase an unbroken market-clearing price; endogenous to guarantee that the bidders themselves determine the market-clear price. ${ }^{9}$

Our random $n$ th-price auction works as follows: (1) each bidder submits a bid (offer); (2) each bid (offer) is rank-ordered from lowest to highest; (3) the monitor selects a random number - the $n$ in the $n$ th-price auction, uniformly-distributed between 2 and $n$ ( $n$ bidders); and (4) in the WTP case, the monitor sells one unit of the good to each of the (n-1) highest

\footnotetext{
${ }^{9}$ List and Shogren (1998) use the random $n$ th-price auction when buying back gifts to test for deadweight loss of Christmas.
} 
bidders at the $n$ th-price; in the WTA case, the monitor buys one unit each from the ( $n-1)$ lowest bidders and pays the $n$ th-lowest bid. And lab evidence suggests the auction can work — bidders revealed sincere bids, and off-the-margin bidders were more engaged relative to the standard second price mechanism. ${ }^{10}$

We use the random $n$ th-price treatments to explore bidding behavior given, we have addressed potential shortcomings of the second price auction, like not engaging infra-marginal bidders. And if the second-price auction forces values to converge when they should not, the random $n$ th-price auction should remove these incentives by randomizing the market-clearing price and engaging each bidder. Bidders should have incentive to bid sincerely because they cannot chase a random market-clearing price, and each bidder should be engaged because everyone has a chance to buy a unit of the good and they determine the price endogenously.

We constructed the random $n$ th-price treatment to match the two other treatments, except for the obvious switch of the auction mechanism. Table 1 summarizes the random $n$ th-price experiments, which were run in four sessions on the same day at the University of Central Florida with a total of 40 subjects.

Table 4 summarizes the experimental results. We see that bidding behavior was similar to that observed in the second price auction. The initial WTA-WTP gap disappears with experience. We find that the average and median WTA and WTP bids are significantly different through trial 3 for the candy bar and trial 4 for the coffee mug, which does not contradict KKT's concept of an endowment effect

The results then show the WTP and WTA values converged in the last seven trials for candy bars and six trials for coffee mugs. For the candy bar, the median WTA/WTP ratio dropped from nearly 2 to 1 from trial 1 to trial 10 . We cannot reject the null hypothesis that the mean WTP and WTA are equal at even the $10 \%$ confidence level using a $t$-test or a nonparametric Mann-Whitney $U$-test in trials 4-10.

For the coffee mug, the average WTA/WTP ratio decreased to 0.78 in trial 10 from 2.42 in trial 1 . We cannot reject the null in trials 5-10 at the $10 \%$ level using the $t$-test, and we cannot reject the null in trials 2-10 at the 5\% level using the Mann-Whitney $U$-test. ${ }^{11}$ Like behavior in the second price-auction, little value disparity is observed in the random $n$ th-price auction after minimal market experience - average WTP and WTA value measures are not statistically different in the later trials.

\section{Concluding comments}

This paper has evaluated how three auction mechanisms - the Becker-DeGrootMarschak mechanism, the second-price auction, and the random $n$ th-price auction - affect the measurement of willingness to pay (WTP) and willingness to accept (WTA) measures of value. We considered whether anomalous bidding behavior, previously interpreted as

\footnotetext{
${ }^{10} \mathrm{~A}$ companion paper provides more detail on the theory and experimental evidence of the random $n$ th-price auction (Shogren et al., 1999).

${ }^{11}$ Similarly, average WTP and WTA in the random $n$ th-price auction also tend to converge in value - WTP increases $43 \%$ (candy bar) and 78\% (mug) by trial 10, while WTA declines 32\% and $42 \%$ by trial 10 .
} 
Table 4

Summary statistics of the random $n$ th-price auction

\begin{tabular}{|c|c|c|c|c|c|c|c|c|c|c|c|c|}
\hline \multirow[t]{2}{*}{ Good } & \multirow[t]{2}{*}{ Value measure } & & \multicolumn{10}{|l|}{ Trial } \\
\hline & & & 1 & 2 & 3 & 4 & 5 & 6 & 7 & 8 & 9 & 10 \\
\hline \multirow[t]{8}{*}{ Candy } & WTP & Mean (US\$) & 0.69 & 0.70 & 0.68 & 0.74 & 0.68 & 0.88 & 0.91 & 0.93 & 1.01 & 0.99 \\
\hline & $N=20$ & Median & 0.53 & 0.58 & 0.50 & 0.50 & 0.61 & 0.75 & 0.77 & 0.88 & 1.00 & 1.00 \\
\hline & & Variance & 0.30 & 0.26 & 0.33 & 0.45 & 0.31 & 0.45 & 0.48 & 0.51 & 0.47 & 0.52 \\
\hline & WTA & Mean & 1.29 & 1.33 & 1.26 & 1.07 & 0.93 & 1.05 & 1.06 & 1.05 & 0.88 & 0.88 \\
\hline & $N=20$ & Median & 1.00 & 1.13 & 1.12 & 1.00 & 1.00 & 0.99 & 0.88 & 0.87 & 0.99 & 1.00 \\
\hline & & Variance & 0.67 & 0.64 & 0.56 & 0.45 & 0.21 & 0.98 & 1.14 & 1.20 & 0.22 & 0.20 \\
\hline & Ratio of mean WTA/WTP & & 1.87 & 1.90 & 1.85 & 1.44 & 1.36 & 1.20 & 1.15 & 1.13 & 0.87 & 0.89 \\
\hline & $t$-test of means & & $-2.7^{\mathrm{b}}$ & $-2.9^{\mathrm{b}}$ & $-2.8^{\mathrm{b}}$ & -1.5 & -1.5 & -0.67 & -0.48 & -0.41 & 0.70 & 0.58 \\
\hline \multirow[t]{8}{*}{ Mug } & WTP & Mean (US\$) & 2.15 & 2.21 & 2.32 & 2.21 & 2.27 & 2.76 & 2.99 & 2.77 & 2.99 & 3.83 \\
\hline & $N=20$ & Median & 1.00 & 1.00 & 1.23 & 1.55 & 2.00 & 2.25 & 2.00 & 3.00 & 2.50 & 3.25 \\
\hline & & Variance & 6.07 & 6.06 & 6.22 & 4.55 & 2.88 & 3.72 & 7.38 & 2.76 & 3.10 & 4.96 \\
\hline & WTA & Mean & 5.21 & 4.62 & 4.19 & 4.29 & 3.63 & 3.35 & 3.37 & 2.63 & 2.98 & 3.02 \\
\hline & $N=20$ & Median & 5.03 & 4.50 & 3.75 & 3.53 & 3.00 & 2.50 & 2.03 & 2.00 & 2.35 & 2.00 \\
\hline & & Variance & 12.69 & 11.83 & 10.98 & 12.94 & 11.72 & 5.97 & 6.09 & 4.64 & 5.70 & 5.80 \\
\hline & Ratio of mean WTA/WTP & & 2.42 & 2.08 & 1.81 & 1.93 & 1.60 & 1.21 & 1.12 & 0.95 & 0.99 & 0.78 \\
\hline & $t$-test of means ${ }^{\mathrm{d}}$ & & $-3.1^{\mathrm{b}}$ & $-2.5^{\mathrm{b}}$ & $-2.0^{\mathrm{d}}$ & $-2.2^{\mathrm{c}}$ & -1.6 & -0.84 & -0.46 & 0.23 & 0.01 & 1.10 \\
\hline
\end{tabular}

${ }^{a} \mathrm{H}_{0}:$ mean $_{\mathrm{WTP}}-$ mean $_{\mathrm{WTA}}=0 ; \mathrm{H}_{\mathrm{A}}:$ mean $_{\mathrm{WTP}}-$ mean $_{\mathrm{WTA}}<0$

t-test: reject $\mathrm{H}_{0}$ at the $1 \%$ level; Mann-Whitney $U$-test: reject $\mathrm{H}_{0}$ at the $1 \%$ level.

${ }^{c} t$-test: reject $\mathrm{H}_{0}$ at the $5 \%$ level; Mann-Whitney $U$-test: reject $\mathrm{H}_{0}$ at the $5 \%$ level.

${ }^{\mathrm{d}}$ t-test: reject $\mathrm{H}_{0}$ at the $10 \%$ level. 
evidence of a fundamental endowment effect, is still observable and persistent for alternative incentive compatible mechanisms used to elicit WTP and WTA.

Our experiments show that while initial bidding behavior does not contradict the endowment effect concept, the effect can be eliminated with repetitions of a second-price or random $n$ th-price auction. These results suggest that no fundamental endowment effect exists if the thesis is correct that the effect should persist across auction mechanisms and across trials. Our findings suggest that the auction mechanism itself can account for the conflicting observations in Kahneman et al. (1990) and Shogren et al. (1994a). Determining exactly why three theoretically incentive compatible mechanisms might or might not be demand-revealing in practice points to needed research that develops a thorough theory of bidding behavior and runs additional lab work to test out its predictions.

\section{Acknowledgements}

Financial support provided by ERS/USDA, NSF grant SBR 94-22813, and the Food Safety Consortium (USDA). Jack Knetsch, Glenn Harrison, and three reviewers supplied helpful comments. All errors remain our own.

\section{References}

Becker, G., DeGroot, M., Marschak, J., 1964. Measuring utility by a single response sequential method. B. Sci. 9, 226-236.

Brookshire, D., Coursey, D., 1987. Measuring the value of a public good: an empirical comparison of elicitation procedures. Am. Econ. Rev. 77, 554-566.

Cherry, T., Frykblom, P., List, J., Shogren, J., Williams, M., 2000. Bidding behavior in a second-price auction with an outside option, Working Paper, University of Wyoming (photocopy).

Coursey, D., Hovis, J., Schulze, W., 1987. The disparity between willingness to accept and willingness to pay measures of value. Q. J. Econ. 102, 679-690.

Franciosi, R., Isaac, R.M., Pingry, D., Reynolds, S., 1993. An experimental investigation of the Hahn-Noll revenue neutral auction for emissions licenses. J. Environ. Econ. Manage. 24, 1-24.

Grether, D., 1994. Individual behavior and market performance. Am. J. Agric. Econ. 76, 1079-1083.

Hanemann, W.M., 1991. Willingness to pay and willingness to accept: how much can they differ? Am. Econ. Rev. 81, 635-647.

Hoffman, E., Menkhaus, D., Chakravarti, D., Field, R., Whipple, G., 1993. Using laboratory experimental auctions in marketing research: a case study of new packaging for fresh beef. Marketing Sci. 12, 318-338.

Kagel, J., 1995. Auctions: a survey of experimental research. In: Kagel, J., Roth, A. (Eds.), Handbook of Experimental Economics. Princeton University Press, Princeton, NJ, pp. 501-585.

Kahneman, D., Knetsch, J., Thaler, R., 1990. Experimental tests of the endowment effect and the Coase theorem. J. Pol. Econ. 98, 1325-1348.

Knetsch, J., Sinden, J., 1984. Willingness to pay and compensation demanded: experimental evidence of an unexpected disparity in measures of value. Q. J. Econ. 99, 507-521.

Knetsch, J., Tang, F.-F., Thaler, R., 1998. The endowment effect and repeated market trials: is the Vickrey auction demand revealing? Working Paper, Simon Fraser University (photocopy).

List, J., Shogren, J., 1998. The deadweight loss of christmas: comment. Am. Econ. Rev. 88, 1350-1355.

List, J., Shogren, J., 1999. Price information and bidding behavior in repeated second-price auctions. Am. J. Agric. Econ. 81, 942-949.

Milgrom, P., Weber, R., 1982. A theory of auctions and competitive bidding. Econometrica 50, 1089-1122. 
Miller, G., Plott, C., 1985. Revenue generating properties of sealed-bid auctions: an experimental analysis of one-price and discriminative auctions. In: Smith, V.L. (Ed.), Research in Experimental Economics. Vol. 3, JAI Press, Inc., Greenwich, CT, pp. 159-182.

Plott, C., 1986. Laboratory experiments in economics: the implication of posted-price institutions. Science 232, 732-738.

Randall, A., Stoll, J., 1980. Consumer's surplus in commodity space. Am. Econ. Rev. 71, 449-457.

Shogren, J., Hayes, D., 1997. Resolving differences in willingness to pay and willingness to accept: reply. Am. Econ. Rev. 87, 241-244.

Shogren, J., Koo, C., Margolis, M., List, J., 1999. A random nth-price auction. Working Paper, University of Wyoming (photocopy).

Shogren, J., Shin, S., Hayes, D., Kliebenstein, J., 1994a. Resolving differences in willingness to pay and willingness to accept. Am. Econ. Rev. 84, 255-270.

Shogren, J., Fox, J., Hayes, D., Kliebenstein, J., 1994b. Bid sensitivity and the structure of the Vickrey auction. Am. J. Agric. Econ. 76, 1089-1095.

Smith, V.L., 1982. Microeconomic systems as an experimental science. Am. Econ. Rev. 72, 589-597.

Vickrey, W., 1961. Counterspeculation, auctions, and competitive sealed tenders. J. Finan. 16, 8-37.

Willig, R., 1976. Consumer's surplus without apology. Am. Econ. Rev. 66, 589-597. 